\title{
The Transgenerational Object
}

\author{
Helen Lazaratou, Dimitris C. Anagnostopoulos \\ Community Mental Health Centre, University of Athens, Athens, Greece
}

\begin{abstract}
From a viewpoint of Freudian metapsychology, this paper aims to carry out a bibliographic review on transgenerational transmission and to demonstrate — by the means of a clinical case — how pathology is created. The transgenerational object consists of a predecessor, a direct or indirect relation from previous generations who creates fantasies and provokes identifications in one or more members of the family. Usually he/she is the result of keeping a secret. Sigmund Freund does not refer directly to the transgenerational object. In many parts of his work, however, he uses transgenerational references to discuss the organization of the mental function, either on a personal or group basis. After S. Freud, various psychoanalysts have concerned themselves with transgenerational transmission under many different prisms, mainly in an attempt to explain the mechanisms which may lead to the expression of pathology. In transgenerational transmission, pathology is founded on the presence of a secret which in turn is connected to some form of unresolved grief. Secrets attempt to cover some narcissistic wound, a downgrading of the family image which they do not wish to transfer. With his/her symptoms, the child does not express his/her own conflicts but somebody else's. By the means of a clinical case, we discussed the contribution of a family secret to the pathogenesis of a depressive episode during adolescence.
\end{abstract}

Keywords: Freudian metapsychology, transgenerational transmission, family secrets, psychic pathology

\section{Genealogy}

The sense of genealogy is a psychological phenomenon established within a social setting.

There are three dimensions to the definition of genealogy: (1) the biological; (2) the legal, which is necessary and different in each social system; and (3) the psychological, which is based on identifications and is mostly unconscious. As P. Legendre (1985) writes in his book L'inestimable Objet de la Transmission regarding the social condition: "It is not enough to reproduce the human flesh but one must also establish it legally".

Genealogy is the nucleus of belonging. The family tree, a common name, a common religion, traditions, a common language-All create group cohesion.

Genealogy holds the string of life; it gives the subject its rightful place. In order for it to function, over two generations are involved. When a child is born, the subject of three generations is required to play a preconceived role, to take his/her place in a chain of unconscious identifications, to be recognized separately by his/her father, who is required to give up his place and yield it to his child.

Denying the impact of genealogy causes identity rejection, a potentially psychotic experience.

Helen Lazaratou, Associate Professor of Child Psychiatry, Faculty of Medicine, 1st Department of Psychiatry, Community Mental Health Centre, University of Athens.

Dimitris C. Anagnostopoulos, Associate Professor of Child Psychiatry, Faculty of Medicine, 1st Department of Psychiatry, Community Mental Health Centre, University of Athens. 


\section{The Transgenerational Object}

The transgenerational object consists of a predecessor, a direct or indirect relation from previous generations who creates fantasies and provokes identifications in one or more members of the family. Usually he/she is the result of keeping a secret. One of the parents, usually out of shame, wished to protect the child from any mentioning of this object. This predecessor may have committed some illegal act, died young, may have been illegitimate or the perpetrator or victim of sexual violence, and also have committed suicide or anything else that may be experienced as traumatic and be shameful for the parents.

Thus, these representations on which the transgenerational object is recorded on the parents' psyches refer to a painful trauma and are judged to be morally unethical. In the next generations, there is a lack of representation or a proto-representation of this event which cannot be verbalized. In the family, all the members are consciously or unconsciously affected. Each member holds a piece of this memory, some word which connects it or begins a quest which provokes reveries and constructions.

Very often these events are accompanied by mythical headings with an allegorical function which lend certain cohesion to the memory. The representations are projected and create unconscious bonds within the family. Each member addresses the other members with such a relationship model in mind. In such cases, the transgenerational representations have a structural role and may be found at the basis of the family's difficulties.

Each family has a mythical self-image, imaginary or ideal, which connects it with the family tree. If a family has a secret, it wishes to deny its roots, to reject its family tree. This can only provoke symptoms, conflicts, personal, and group dissatisfaction.

\section{Historical Background}

Sigmund Freund does not refer directly to the transgenerational object. In many parts of his work however, he uses transgenerational references to discuss the organization of mental function either on a personal or group basis. The child's superego according to Freud is based on his/her parents' superego. If one assesses "the father's law" in the formation of the superego, we can easily discern that the child does not in fact identify only with the father's image, but also with the forbidding message, which has been handed down from parent to parent, that is, from the child's predecessor, the grandparent. Surely, the superego is not solely based on identifications: It is certainly more than that. One can, however, identify the genealogical chain and the way that a message may be conveyed from one's predecessors.

In 1914, Sigmund Freud wrote in the Introduction to Narcissism: "The subject has a double function, on the one hand it is its own self with its own aims and on the other it is a link in the chain which is used against desire, or at least that is against its wishes". The distinction between the sexual drive of the ego is reflected in this double function of the individual. Self-preservation refers to the body and sexuality refers to the relationship with the group.

In Totem and Taboo (1913), Freud suggests that the relationship between generations contributes to the structure of the subject's psyche. It makes the group go forward as far as the deepest roots of intra-psychic differentiation are concerned, and he refers to the guilt which is transferred from one generation to the other.

At the end of his life, in Moses and the Monotheism (1939), Freud underlines one more time: "Man's 
ancient heritage does not only include intentions, but also their content, mnemonic vestiges regarding the experiences of previous generations". It appears, therefore, that throughout his whole work Freud takes into account the personal as well as the communal roots of identity.

After Freud, various psychoanalysts have treated transgenerational transmission under many different prisms, mainly in an attempt to explain the mechanisms which may lead to the expression of pathology. The best-known - and possibly the most important - addition on this subject was that made by Abraham and Torok (1971; 1978), who spoke of the "crypt". They claim that a predecessor either in the past or the recent past committed some despicable act, which, however, has remained a secret and is unknown by all. A child or adult adopts behaviours which are incomprehensible to the environment but remarkably reminiscent of this predecessor's behaviour. Nevertheless, this person has never met or been spoken to of the predecessor. This is a person who acts as his "ghost", as the central personage in an unresolved grief, a lifeless, intact body in a crypt. The libidinal investment of the predecessor absorbs all of the psychological functioning of the subject and does not allow them to continue with their thought processes. Thus, this empty representation, the lack of ability to think on this subject may lead to a delusion or to some other psychotic or psychosomatic symptom.

Alain de Mijolla (1981) writes about Les Visiteurs du Moi (The Ego's Visitors), visitors on which unconscious identifications are based. He attempts to define the meta-psychological conditions of the transmission from clinicians' retrospective data, taking into account the dynamics of genealogy in three successive generations which are necessary for the construction of the subject.

A. de Mijolla does not comply with the notion of an inviolate, steady and rigid identity which takes its place after the completion of the Oedipal stage. He suggests that there is a dynamic process which is capable of adopting several successive models of known and unknown persons for the subject, which are however carefully stored in the "closed drawers" of family memory. These persons incite reveries and fantasies made by all members of the same family, creating scenarios which are maintained for more than one generation.

Through the same prism of identifications, Baranes (1989) wrote: "The transgenerational process establishes the other person present in the Ego, paradoxically present in each person's structure". Cournut (1983) in Deuils Ratés, Morts Méconnues (Unsuccessful Grief, Unknown Corpses) studied the transgenerational consequences of pathological grief. He spoke also of mournings which were blocked and silent or had never been recognized by one or more intermediate generations.

Finally, H. Fraiberg (1999) wrote about the ghosts in the nursery. According to this author, in infancy there are ghosts or visitors from the parents' forgotten past. It's as if the parent is condemned to repeat the tragedy of his own childhood. It appears that there are ghosts who have established themselves over three or more generations and so it is not easy for them to be recognized as representatives of the parents' past.

As a consequence, parent-infant psychotherapy emerged in the United States during the 1970s, based on the assumption that attachment disorders are a result of the unresolved psychic conflicts of the parents. When there is a "ghost" in the infant's room, the parents have a decreased ability to invest love on their child. The ghosts represent unknown or incomplete memories which may be found outside the field of consciousness. They continue, however, to influence the parents' self-representation and are expressed in the context of their closest relationships.

Recently, we can see that, beyond the individual, the social discourse may transfer the trauma from one generation to the next. W. Bohleber (2007) describes the transgenerational effects of the traumatic nature of the Holocaust on post-war German society. 


\section{The Transmission via the Name}

\section{Giannis's Case}

"Giannis was 16 years old, a 5th grade high school student, when he was referred for therapy. During the past few months, his academic achievement was quite low, he appeared not to be interested in his classes or his grades. His parents found it peculiar, since up to this point he had been a conscientious young man. His behaviour had also changed over the past months. He was disruptive, irritable, spoke badly and recently he had gotten so upset that he had broken his guitar, which he loved dearly. He had isolated himself from his friends and spent a lot of time in bed without sleeping, listening over and over to the same piece of music. His parents were extremely alarmed when they found a note in which Giannis wrote that life was not worth living.

Giannis was the second child of a family which did not appear to have any problems. The mother was a teacher who was concerned about her children's academic achievements, and her children in turn rewarded her by being good students. There were no conflicts within the home environment. The older son's adolescence had developed normally. The parents said that they gave him quite a lot of freedom and that he never took advantage of them. Consequently, they were very taken aback by Giannis' problem, as they did not expect it.

Mother says that pregnancy and birth were normal. As is common in Greek tradition, the second son was given the name of the maternal grandfather, whom he had not met since he had died before his parents got married.

As a baby, Giannis was quiet and progressed through all the developmental stages without any problems. He had no adjustment problems in infant school and kindergarten. He was sociable and took part in group games. In primary school, he showed great performance at maths, which his mother encouraged and sometimes she was particularly oppressive.

He was not prepared for the changes brought on by adolescence. At 16, he still looked and talked like a child. He did not ask for more freedom, he was very shy with girls, and his friends were still of the same sex. He continued to be a good student and studied a lot, until his depressive episode commenced.

While the therapeutic relationship has been established with Giannis and intervention is well under way, his mother insists on seeing the therapist alone. Until that point she had seemed to be dealing with her child's problem phlegmatically. At this session, however, she fell apart. She accuses herself of being an inadequate mother who was unable to protect her child from what she foresaw would happen.

She talks about heredity. Whilst in tears, she explains that her father, whose name Giannis has taken, had presented bipolar disorder. She remembers him always taking medicine, being hospitalized at times, sometimes being loving and tender towards her, and at other times getting furious with her for no apparent reason and hitting her. He committed suicide by jumping off the balcony in their house when she was 13 years old. It was an event which nobody discusses. She has never spoken about it to her husband or his family. According to her own projections, Giannis's mother has preordained his destiny. A central fantasy scenario bonds her with this child".

Giving a grandparent's name to the child is common practice in Greek society. Naming is the first verbalization, which sets the person as a separate being, his or her first symbolic record. At the same time, the name is the symbolic transmission of heredity. The belief that some kind of reincarnation takes place from the 
predecessor to the (grand)child is an almost universal belief. In many civilizations, as in Greece, the name of the deceased is given to the first same-sex child who is born. Thus, the name is a link between life and death.

In general, name-giving usually has to do with some predecessor who is already dead or is expected to die before the child is born; it might involve somebody's name in the extended family, or even the name of a non-relative who bears some significance for either parent. The name, therefore, is the vehicle of parental fantasies and desires and may result in being a possibility for identification for the subject. The name seems to carry with it some kind of destiny, whether it is adopted or rejected, accepted or pushed away. Whatever its power, it is a main reference point for a plan which somebody else has decided for it. G. Rosolato (1966) claims that the individual is possessed by the name given to him/her.

\section{The Secret, The Ghost}

Within genealogy, it is necessary to discern the different aspects of transmission: the transmission of genes in biological relationships, the transmission of earthly goods, and the transmission of the surname for legislature.

On a psychological level, that which is transmitted has a positive aspect placed in the object's side (a knowledge, a presence, an object) and a negative aspect, which is narcissistic (a deficiency, a non-object, an absence). Here, what is transmitted is that which is missing, that which has not been said. "Continuity is transmitted through a lack of continuity", said D. Sibony (1986). This way, one can see the family's representation being formed as a group of people determined to be silent on the same matter and recognizing each other through this agreement on silence. The feeling of being part of a family tree is not only based on what we know impartially about this particular genealogy, but also on what we do not know, as if the confirmation of belonging may come from the blanks and spaces of the other's language. These representations are projected, forming unconscious bonds within the family. Each member addresses the other members within this relationship model. Here the transgenerational representations have a structural role and can be found at the basis of family difficulties.

In Giannis's case, his mother tried to protect her son from any reference to the transgenerational object. Her father had committed suicide and that fact had been a traumatic event and had provoked feelings of shame. According to A. Eiguer (1989), when the representations which the transgenerational object has coded on the parents' psyche refer to a painful trauma or loss are morally damning for the next generations, there is a lack of representation which is unable to be verbalized.

In transgenerational transmission, pathology is founded on the presence of a secret which in turn is connected to some form of unresolved grief. The secret is not personal or intra-psychic, as it involves the relationship with someone else: If there is no "someone else", there is no secret. It has a certain power on the other person, who is connected to a threat: the uncovering of the secret. In transgenerational transmission, it is the guilt which secrets carry and that very same guilt which influences their disclosure.

Secrets attempt to cover some narcissistic wound, some downgrading of the family image which they do not wish to transfer. Here, ghosts live on the non-representations of the objects, the spaces, and the non-representable feelings of emptiness. The child expresses with his symptoms not his own conflicts but somebody else's: those of a predecessor who is living in him, like a castle haunted by a ghost.

In these cases, the secret is the thing which cannot be shared with the other through words and is therefore transferred and haunts the others' lives. Maria Torok (1968) states: "Within the belly of the crypt, they stand speechless, like owls, ready restless words buried alive". In fact, it is about the repression of conservation, not 
an active repression, according to Freud, where the "past-present" forms a solid lump of buried reality. As impossible to be reborn as it is to turn into dust.

In this intrapsychic cave, in this crypt, "All the words which could not be spoken, all the scenes which could not be brought back to memory, all the tears which could not be shed" remain enclosed and hidden. It could be an unspoken grief which is found, in the crypt's genesis, at the very centre of the subject.

And it is in the form of a ghost that it will reappear in the next generations. The ghost is a construction of the unconscious whose peculiarity is that it can never be conscious or the result of transference, whichever way one were to define this, from the parent's unconscious to the child's unconscious. Nevertheless, these ghosts are invented by the living and are created by the blank spaces which others' secrets leave inside us. The appearance of these ghosts is connected to the death drive and constitutes a narcissistic destruction. The ghost is a corpse buried within the other, reappearing on this earth to haunt the living.

But the relationships around this secret are more interesting than the secret itself. The disclosure of the secret can make the parents fear a repetition of the traumatic act, the family's decadence, the arrival of a new period of unhappiness within the family. The central problem is that of personal psychological economy, of investments and désinvestissements.

In such families, the désinvestissements - due to investment in the ghost and the defensive attempt to build a relationship for the ghost to live in - do not leave enough libidinal energy available for the external object, i.e., the child. So the child either feels an emotional gap or a narcissistic overinvestment. In that case, he does not have the right to exist outside of what his parents have projected on him.

The father or mother, absorbed as they are by the ghost, are not available for primary identification, which is necessary for the construction of an object-like relationship capable of sustaining empathy and familiarity. Everything functions within narcissistic identifications which confuse the ego with the other.

To conclude, the crypt touches two pairs of opposite psychological processes. On one hand, the transgenerational violence towards the transgenerational symbolic message, and on the other, the narcissistic identification over the primary identification.

B. Golse (1999) writes: "It is not only from that which is missing or which fails that transmission is achieved but also from that which is not completed, that which does has not been written on or represented or on that which is stationary, on stand-by without having been recorded".

So transgenerational transmission of life enhances structural identifications and can be non-conflicting, whilst the transgenerational transmission of death, provoking alienating identifications, is conflicting and leads to pathology. Transgenerational transmission is therefore helpful both for the better and for the worse. It may help in the structure and the freedom of the individual or it may be paralytic and deadly.

\section{The Trangenerational in Giannis's Case}

B. Shapiro (2003) describes the case of an adolescent who presented a paralyzing chronic pain. The psychosomatic problem was not a single entity but comprised diverse interwoven elements, among which the transgenerational transmission of trauma held centre stage.

In Giannis's case, the onset of the depressive episode was in adolescence, a period when narcissistic identifications prevail. We are aware that narcissistic identification provokes the substitution of the Ego by the object and cancels the representation of the object. In fact, it may be found at the nucleus of the grieving process. 
Adolescence is often described in terms suiting the description of a depressive episode. When studying adolescence, one spontaneously refers to sadness, irritability, anger, pessimism, and low self-esteem.

A large part of the adolescent process is similar to the mourning process. The adolescent is required symbolically to separate from his parents and remove himself from the cocoon of his childhood years in order to face the new reality on his own. This process of breaking previous bonds has similar stages as the process of coping with the loss of a loved one.

Despite the similarities, however, there is a dynamic process as well. The adolescent gradually goes through the processes which will lead him away from this painful situation. However, in Giannis's case we were faced with an authentic depressive episode with psychiatric symptomatology. But the question still remains: Did the mother's concern worsen an otherwise "normal adolescent depressive episode"? Did the tragedy which occurred during the mother's adolescence "have" to be repeated in Giannis's adolescence as well? Were the maternal projections so powerful as to drive Giannis into a depressive episode?

D. Houzel (1996) writes on the existence of the family envelope in parallel to that of the individual psychic one, in which all the members of a family are contained in a common identity and thus the children are protected from pathogenic transgenerational repetition.

Giannis's grandfather had bipolar disorder. The genetic basis of this disorder cannot be denied. However, whether a depressive period during adolescence may be the beginning of a bipolar disorder can be discerned only longitudinally.

What is important is that Giannis's destiny is not considered preordained. Giannis should not be bound to his predecessor's heredity either for biological reasons - that is, of genetic heredity-or for reasons of transgenerational transmission. This is where the challenge of therapeutic intervention comes into play: to be able to invoke motion into the transgenerational and to allow it to participate in life and living.

\section{References}

Abraham, N., \& Torok, M. (1978). L'écorce et le noyau. Paris, Aubier Flammarion.

Abraham, N., \& Torok, M. (1971). De la topique realitaire: Notations sur une métapsychologie du secret. Rev. Fr. Psychol, 35, 977-982.

Badoni, M. (2002). Parents and their child and the analyst in the middle: Working with a transgenerational mandate. Int. J. Psychoanal, 83, 1111-1131.

Baranes, J. J. (1989). Difficult cases in psychoanalysis: Those who bear the scars from the analyst's couch. Revue Francaise de Psychanalyse, 53, 695-704.

Bohleber, W. (2007). Remembrance, trauma and collective memory: The battle for memory in psychoanalysis. Int. J. Psychoanal, $88,329-52$.

Cornut, J. (2007). Deuils rates, morts méconnues. Bulletin de S.P.P., 2, 9-25.

De Mijolla, A. (1986). Les visiteurs de moi. Paris, Edit Les Belles Lettres.

Eiguer A. L. (1989). L'objet transgenerationnel. Perspectives Psychiatriques, 17(11), 108-115.

Fraiberg, H. (1999). Fantômes dans la chambre des enfants. Paris, Edit. P.U.F, Coll "Le fil rouge".

Freud, S. (1913). Totem and taboo. In J. Stratchey (Ed. and trans.), The standard edition of the complete psychological works of Sigmund Freud (Vol. 24). London, Hogarth Press.

Freud, S. (1914). On narcissism. In J. Stratchey (Ed. and trans.), The standard edition of the complete psychological works of Sigmund Freud (Vol. 24). London, Hogarth Press.

Freud, S. (1913). Moses and monotheism. In J. Stratchey (Ed. and trans.), The standard edition of the complete psychological works of Sigmund Freud (Vol. 24). London, Hogarth Press.

Golse, B. (1999). Du corps a la pensée. Paris, Edit. P.U.F, Coll "Le fil rouge".

Houzel, D. (1996). The family envelope and what happens when it is torn. Int. J. Psychoanal, 77, 901-912. 
Legendre, P. (1985). L'inestimable objet de la transmission. Paris, Edit, Fayard.

Rosolato, G. (1966). The father. Evol Psychiatr, 31, 469-92.

Sibony, D. (1986). Transmission d'inconscient et généalogie in Guyotat, J., Fedida, P., Mémoires transferts. Paris, Edit. Echo-Centurion, 57-68.

Smirnoff, V. (1976). Le squelette dans le placard. Nouv. Rev. Psychanal. 14, 27-53.

Shapiro, B. (2003). Building bridges between body and mind: The analysis of an adolescent with paralysing chronic pain. Int. J. Psychoanal, 3, 547-61.

Torok, M. (1968). Maladie du deuil et fantasme du cadavre exquis. Revue Française de Psychanalyse, XXXII, No 4, 715-733. 